\title{
MODELO DE SIMULAÇÃO DE SECAGEM DE PRODUTOS AGRÍCOLAS USANDO ENTALPIA DO AR CONSTANTE
}

\section{VALDECIR A. DALPASQUALE ${ }^{1}$, DÉCIO SPERANDIO ${ }^{2}$}

\begin{abstract}
RESUMO: A simulação matemática de secagem de produtos agrícolas teve seu auge nas décadas de 1960 e 1970, com destaque para os modelos de Thompson e de Michigan. Entretanto, nenhum deles abordou a condição de entalpia constante do ar de secagem durante o processo, limitando-se a conferir se a umidade relativa do ar não excedia 100\%. Estudos conduzidos na Universidade Estadual de Maringá permitiram concluir que os balanços de energia e de massa de um processo de secagem estão incluídos no uso da mesma entalpia do ar durante a secagem, ajustando-se, com ela, a umidade absoluta do ar em função da umidade removida do produto. Com essa nova razão da mistura do ar e com a entalpia constante, avalia-se a nova temperatura do ar de secagem na saída da camada e, com essas duas propriedades psicrométricas, a umidade relativa do ar. Se ela atingir a condição saturada, encerra-se o processo de secagem naquele tempo, a partir daquela posição. Os resultados obtidos por simulação foram conferidos com resultados experimentais de secagem de milho em camadas fixas, com elevada concordância entre eles.
\end{abstract}

PALAVRAS-CHAVE: simulação de secagem, novo modelo.

\section{DRYING SIMULATION MODEL OF AGRICULTURAL PRODUCTS WITH CONSTANT AIR ENTHALPY}

\begin{abstract}
Mathematical drying simulation of agricultural products reached its highest point in the decades of 1960 and 1970, with prominence for MSU and Thompson's models. However, none of them used the constant enthalpy condition of drying air during the process, being limited to checking if the relative humidity of the air did not exceed $100 \%$. Studies conducted in the State University of Maringá allowed to conclude that energy and mass balances of a drying process are included when using the same air enthalpy in such process. The absolute humidity of the air is adjusted as a function of the removed humidity of the product. With that new absolute humidity of the air and with the constant enthalpy, the new temperature of the drying air is evaluated in the exit of the layer and, with those two psychrometric properties, the relative humidity of the air. If it reaches the saturated condition, the drying process is stopped at that time and position. The results obtained by simulation were checked against experimental results of corn dried in fixed-bed layers, with high agreement among them.
\end{abstract}

KEYWORDS: drying simulation, new model.

\section{INTRODUÇÃO}

A secagem de produtos agrícolas é um processo que pode demorar desde algumas horas até vários dias, dependendo da técnica usada e dos seus parâmetros. Ao se investigar a melhoria de qualquer uma dessas técnicas, pode-se gastar tempo considerável, se elas forem repetidas fisicamente. Entretanto, a simulação matemática de secagem permite fazer a otimização desses processos em tempo significativamente menor e de maneira econômica. Essa maneira científica de descrever a secagem de produtos agrícolas foi amplamente investigada nas décadas de 1960 e 1970, quando foi também muito bem discutida na bibliografia (BROOKER et al.(1974), BAKKERARKEMA et al. (1978), HAWK et al. (1978), MOREY et al. (1978) e VAN EE \& KLINE (1979)). Os modelos semi empíricos propostos por THOMPSON (1967) são ainda bastante populares, para

\footnotetext{
${ }^{1}$ Ph.D., Prof. Titular, Departamento de Agronomia, Universidade Estadual de Maringá, valdecir.dalpasquale@ gmail.com.

${ }^{2}$ Magnífico Reitor da Universidade Estadual de Maringá, Prof. Assistente, Departamento de Administração.

Recebido pelo Conselho Editorial em: 3-11-2008

Aprovado pelo Conselho Editorial em: 21-5-2010
} 
diferentes tipos de secagem. THOMPSON (1972) apresentou alterações significativas no modelo para simulação de secagem com ar ambiente. Ele passou a ser conhecido como o Modelo de Thompson para Armazenagem, porque incorpora avaliações de deterioração do produto, por respiração. Além disso, é rápido porque não usa equação de secagem em camadas finas, mas um algoritmo que avalia com precisão as condições de equilíbrio para as situações de secagem e reumedecimento do produto.

O modelo de Michigan, desenvolvido por BROOKER et al. (1974) a partir de transferência simultânea de energia e massa, é composto por quatro equações diferenciais que permitem descrever as condições de energia e de umidade do ar de secagem e do produto sendo secado. $\mathrm{Na}$ época, foi considerado excelente para a simulação de processos rápidos de secagem, mas sofreu restrições para a simulação de secagem com ar ambiente, pela elevada demanda de tempo computacional. Com o avanço da informática, esse problema foi superado. O modelo de MOREY et al. (1976) é um aperfeiçoamento do Modelo de Thompson para Armazenagem, porque incorporou a equação de secagem em camadas finas de Sabbah. Com isso, é capaz de simular condições de secagem com fluxos de ar mais elevados.

Quase 30 anos mais tarde, SPERANDIO (2005) desenvolveu estudos de secagem em camadas fixas e em fluxos cruzados, usando os modelos de Thompson e de Michigan, mas adicionou a condição do ponto de estado do ar mover-se ao longo da linha de mesma entalpia, durante a secagem. As vantagens do uso da entalpia constante na simulação de secagem, como maior flexibilidade na definição dos intervalos de tempo e de espaço, assim como a não distorção dos balanços de energia e massa foram mostrados por DALPASQUALE et al. (2009).

O uso do modelo de Thompson com entalpia constante foi apresentado por DALPASQUALE \& SPERANDIO (2007). A solução matemática do modelo de Michigan com entalpia constante foi discutida por DALPASQUALE et al. (2009b). Todos esses estudos foram desenvolvidos na Universidade Estadual de Maringá, em Maringá, Paraná.TOMKIEWICZ \& RYNIEKI (2007) apresentaram um modelo matemático estocástico capaz de estimar com precisão a umidade de centeio em um silo, com base nas mudanças na temperatura do ar de secagem, quando secado com ar ambiente. Eles também usaram o critério de entalpia do ar constante durante a secagem, mas não enfatizaram a importância do seu uso.

Nos modelos matemáticos para a simulação de secagem que popularizaram essa técnica, não se usa entalpia do ar constante, durante a secagem. Observa-se apenas se a umidade relativa do ar não excede $100 \%$. Nos modelos de Sperandio e naquele de Tomkiewicz e Rynieki, usa-se a entalpia do ar constante durante a secagem, simultaneamente com balanços de energia e massa e critérios estocásticos. SPERANDIO (2005) menciona não distorções nos balanços de energia e massa ao usar, além desses balanços, a entalpia do ar constante.

Em vista disto, o presente trabalho tem por objetivo apresentar um novo modelo para simulação matemática de secagem de produtos agrícolas que usa somente a condição de entalpia do ar constante durante o processo, em substituição aos balanços de energia e massa entre o ar de secagem e o produto sendo secado. A validação do modelo será verificada pela comparação dos resultados simulados com outros experimentais apresentados por MARTINS et al. (1999).

\section{MATERIAL E MÉTODOS}

Neste trabalho, são simulados resultados de secagem de milho em camadas fixas, em altas temperaturas, a partir de diferentes umidades iniciais, usando diferentes condições de secagem, conforme resultados experimentais publicados. O modelo faz estimativas da umidade de produto. O processo é simulado de acordo com os seguintes passos:

1. Identificar a umidade absoluta do ar, a partir de sua condição original de temperatura e umidade relativa;

2. Estabelecer a temperatura de secagem; 
3. Com essa temperatura e umidade absoluta do ar, calcular a entalpia do ar de secagem, que será mantida constante durante todo o processo;

4. Calcular a umidade relativa do ar para a primeira camada;

5. Calcular a umidade removida do produto com as condições do ar aquecido;

6. Adicionar essa umidade removida à umidade absoluta do ar, usando um critério de proporcionalidade entre a massa específica do produto, em unidades de matéria seca, e a quantidade de ar seco sendo usado;

7. Calcular a temperatura do ar de secagem na saída da camada, rearranjando a equação da entalpia. Essa temperatura será a mesma para a secagem da camada seguinte;

8. Com essas novas temperatura e umidade absoluta do ar. Verificar se a umidade relativa é inferior a $100 \%$. Em caso positivo, a secagem continua para a camada seguinte, no mesmo tempo de secagem. Caso contrário, inicia-se a simulação de secagem para o tempo seguinte, a partir da primeira camada;

9. Repetir as avaliações a partir do passo 5, até que o critério final de secagem seja atingido, quer seja ele a duração do processo, ou a umidade final desejada.

Usou-se este procedimento para simular os resultados experimentais de MARTINS et al. (1999), mostrados na Tabela 1 , usando-se $20 \mathrm{~m}^{3} / \mathrm{min} / \mathrm{m}^{2}$ de ar de um ambiente, com condições médias de $21^{\circ} \mathrm{C}$ e $65 \%$ de umidade relativa, em uma camada com $0,5 \mathrm{~m}$ de profundidade. Os resultados experimentais são simulados com precisão, desde que se use um coeficiente para ajustar os valores de razão de umidade do produto, estimados pela curva de secagem em camadas finas. Neste trabalho, as estimativas de umidade do produto foram feitas pela equação de Page, multiplicadas pelo coeficiente proposto:

$$
\mathrm{RU}=\xi \mathrm{e}^{-\mathrm{kt} \mathrm{t}^{\mathrm{n}}}
$$

em que,

$$
\begin{aligned}
& \mathrm{k}=-3,47 \times 10^{-2}+2,75 \times 10^{-3}(\mathrm{~T} \times 9: 5+32) \\
& \mathrm{n}=0,54+3,24 \times 10^{-3} \mathrm{UR} ; \\
& \mathrm{T} \text { - temperatura do ar, }{ }^{\circ} \mathrm{C} ; \\
& \mathrm{UR} \text { - umidade relativa do ar, decimal, e } \\
& \mathrm{t} \text { - tempo de secagem, horas. }
\end{aligned}
$$

TABELA 1. Tempo de secagem (h) e umidade final (\%) obtidos em camadas de milho com diferentes umidade iniciais e submetidas a distintas temperaturas de secagem $\left({ }^{\circ} \mathrm{C}\right)$.

Drying time (h) and final moisture content (\%) obtained in layers of corn with different initial moisture content and subjected to different drying temperatures $\left({ }^{\circ} \mathrm{C}\right)$.

\begin{tabular}{ccc}
\hline Temperatura de Secagem & Tempo de Secagem & Umidade Final \\
\hline & Umidade inicial $=35 \%$ & \\
700 & 5,78 & 12,98 \\
40 & 7,24 & 12,99 \\
100 & 14,10 & 12,82 \\
70 & Umidade inicial $=25 \%$ & 12,82 \\
40 & 3,77 & 12,98 \\
100 & 5,32 & 12,99 \\
70 & 11,27 & 12,98 \\
40 & Umidade inicial $=18 \%$ & 12,98 \\
\hline
\end{tabular}


A umidade de equilíbrio foi avaliada pela equação de Henderson modificada (SPERANDIO, 2005):

$$
U e=\left[\frac{\ln (1-U R)}{-k \cdot(T+c)}\right]^{\frac{1}{n}}
$$

em que,

$\mathrm{k}-0,4713$;

c - 49,81, e

$\mathrm{n}-1,8634$.

O valor do parâmetro $k(0,4713)$ foi determinado pelos autores, a fim de se expressar a umidade de equilíbrio em base seca, na forma decimal, uma vez que expressar em porcentagem base seca é incorreto. A temperatura e a umidade relativa são usadas com as mesmas unidades da eq.(1). A entalpia do ar de secagem foi estimada pela seguinte equação (SPERANDIO, 2005):

Ent $=1.006,76 \mathrm{~T}+\mathrm{UA}(2502086,97+1862,79 \mathrm{~T})$ em que,

Ent - entalpia do ar, $\mathrm{J} / \mathrm{kg}_{\text {a.s. }}$;

UA - umidade absoluta do ar, $\mathrm{kg}_{\mathrm{v}} / \mathrm{kg}_{\mathrm{a} . \mathrm{s} .}, \mathrm{e}$

$\mathrm{T}$ - temperatura do ar, ${ }^{\circ} \mathrm{C}$.

\section{RESULTADOS E DISCUSSÃO}

Os resultados experimentais da Tabela 1 foram simulados pelo modelo proposto pela Universidade Estadual de Maringá - UEM, e estão apresentados na Tabela 2.

TABELA 2. Resultados experimentais da Tabela 1, simulados pelo modelo proposto. Experimental results in Table 1, simulated by the proposed model.

\begin{tabular}{cccc}
\hline Temperatura de Secagem & Tempo de Secagem & Umidade Final & Coeficiente \\
\hline \multicolumn{4}{c}{ Umidade inicial $=35 \%$} \\
700 & 5,78 & 12,98 & 0,997748 \\
40 & 7,25 & 12,98 & 0,993 \\
100 & 14,00 & 12,82 & 0,9745 \\
70 & \multicolumn{2}{c}{ Umidade inicial $=25 \%$} \\
40 & 3,75 & 12,83 & 1,0035 \\
100 & 5,31 & 12,98 & 0,99882 \\
70 & 11,25 & 13,00 & 0,99655 \\
40 & Umidade inicial $=18 \%$ \\
\end{tabular}

Diferentes coeficientes foram necessários para estimar com elevada precisão os valores experimentais de umidade final, nem todos com os mesmos números significativos. Esse nível de precisão pode ser observado comparando os valores de tempo de secagem e de umidade final das Tabelas 1 e 2. Conclui-se, então, que a simulação matemática de secagem pode ser feita sem o detalhamento de balanços explícitos de energia e massa entre o produto sendo secado e o ar que faz a secagem, desde que se observe o critério de evaporação adiabática da umidade do produto, pelo ar de secagem. O conceito de evaporação adiabática da umidade inclui implicitamente os balanços de energia e de umidade entre as partes envolvidas. A necessidade de coeficiente para ajustar a razão de umidade do produto indica que a equação 1 e a equação 3 precisam ser ainda aprimoradas, visando à simulação sem o uso de coeficientes para a correção de resultados simulados. 


\section{CONCLUSÕES}

O modelo de simulação de secagem proposto pela Universidade Estadual de Maringá - UEM, reaviva os estudos de simulação de secagem na área agrícola, sem depender de equações algébricas ou diferenciais, para descrever os balanços de energia e massa durante o processo, nem mesmo fazendo explicitamente todos esses balanços, porque eles estão inclusos no conceito de evaporação adiabática da umidade do produto ou de reumedecimento adiabático do ar. Este modelo de simulação de secagem permite a avaliação da umidade do produto durante o processo, sem se preocupar com a temperatura do produto. Por ser simples, pode ser resolvido em calculadoras manuais ou em planilhas.

\section{REFERÊNCIAS}

BAKKER-ARKEMA, F.W.; BROOK, R.C.; LEREW, L. E. Cereal grain drying. In: POMERANZ, Y. (Ed.). Advances in Cereal Science and Technology. St. Paul: American Association of Cereal Chemists, 1978. v.2, p1-45.

BROOKER, D.B.; BAKKER-ARKEMA, F.W.; HALL, C.W. Cereal grain drying. Westport: AVI, 1974. 398 p.

DALPASQUALE, V.A.; SPERANDIO, D. Simulação de secagem de milho em altas temperaturas em camadas fixas sob efeito de entalpia constante, usando modelo de Thompson. Revista Brasileira de Armazenamento, Viçosa - MG, v.32, p.27-36, 2007.

DALPASQUALE, V.A.; SPERANDIO, D.; KOLLING, E. Performance of the Michigan drying simulation model with a new drying rate concept. Acta Scientiarum Agronomy, Maringá, v.31, n.4, 2009.

DALPASQUALE, V.A.; SPERANDIO, D.; MONKEN E SILVA, L.H. Fixed-bed drying simulation with constant enthalpy, using the improved Michigan State University model. Acta Scientiarum Technology, Maringá, v.32, n.3, 2009.

HAWK, A.L.; NOYES, R.T.; WESTELAKEN, C.M.; FOSTER, G.M.; BAKKER-ARKEMA, F.W. The present status of commercial grain drying. In: ASAE SUMMER MEETING. Logan: American Society of Agricultural Engineering, 1978. (Paper 78-3008).

MARTINS, R.R.; FRANCO, J.B.; OLIVEIRA, P.A.V. de. Tecnologia de secagem de grãos. Passo Fundo: Embrapa Trigo/EMATER/RS, 1999. 90 p. (Documentos, 8).

MOREY, R.V.; CLOUD, H.A.; NELSON, W.W. Simulation of solar energy grain drying Minnesota contribution. Final Report for USDA-URS-ERDA Contract n.12 - 1403001-501, 1976.

MOREY, R.V.; KEENER, H.M.; THOMPSON, T. L.; WHITE, G.M.; BAKKER-ARKEMA, F.W. The presente status of grain drying simulation. In: ASAE SUMMER MEETING. Logan: American Society of Agricultural Engineering, 1978. (Paper 78-3309).

SPERANDIO, D. Simulação de secagem de produtos agrícolas em camadas fixas e fluxos cruzados sob efeito de entalpia constante. 2005. 62 f. Tese (Doutorado em Agronomia) - Universidade Estadual de Maringá, 2005.

THOMPSON, T.L. Predicted performance and optimal design of convection grain dryers. 1967. 85 f. Tese (Doutorado em Engenharia Agrícola) - Purdue University, Agricultural Engineering Department, West Lafayette, 1967.

THOMPSON, T. L. Temporary storage of high-temperature shelled corn using continuous aeration. Transactions of the ASAE, St. Joseph, v.15, p.333-337, 1972.

TOMKIEWICZ, D.; RYNIEKI, A. On-line estimation of the moisture content of grain during nearambient drying of the basis of the drying air temperature changes. EJPAU, Varsóvia, v.10, n.3, 
2007. Disponível: <http://www.ejpau.media.pl/volume10/issue3/art-03.html>. Acesso em: 20 maio 2008.

VAN EE, G.R.; KLINE, G. L. Faldry - a model for low-temperature corn drying systems. In: ASAE WINTER MEETING. Ames: American Society of Agricultural Engineering, 1979. (Paper 79-3524). 